\title{
Vocabulary Learning Using Student-Created Class Vocabulary Lists
}

\author{
G. Clint Denison ${ }^{\mathrm{a}}$ and Imogen Custance ${ }^{\mathrm{b}}$ \\ ${ }^{a}$ Mukogawa Women's University; ${ }^{b}$ Kwansei Gakuin University
}

\begin{abstract}
In this article, we describe the pedagogical basis for class vocabulary lists (CVLs) and their implementation using Google Sheets. CVLs allow students to collaborate and build "notebooks" of vocabulary that they feel is important to learn. CVL choices of students $(N=53)$ in three classes of mixed non-English majors and one informatics class were compared against frequency-based lists (British National Corpus/Corpus of Contemporary American English Word Family Lists [BNC/COCA], New General Service List [NGSL], Test of English for International Communication [TOEIC] Service List [TSL]) using the Compleat Web Vocabulary Profiler (Web VP) to determine the usefulness of the selected vocabulary. An information technology keywords list, constructed using AntConc and AntCorGen, was compared against the informatics group's CVL to determine if those students were choosing field-appropriate vocabulary. Results suggest that when given autonomy to choose vocabulary, students generally select useful and relevant words for their contexts (e.g, simulation, virtual, privacy, artificial, denuclearization, aftershock, heatstroke) and that CVLs supplement frequency-based lists in beneficial ways.
\end{abstract}

\section{Background}

In second and foreign language (L2) vocabulary research and instruction, it is generally accepted that learning will be more efficient if the most frequent words are studied first. To this end, much research has served to identify the most frequent English words, producing general purpose lists such as the BNC/COCA (Nation, 2012) and New General Service List (NGSL; Browne, Culligan, \& Phillips, 2013) as well as more specific lists such as the TOEIC Service List (TSL; Browne \& Culligan, 2016). In principle, such lists contain the words that should be learned first in a given context and are vital tools for improving the efficiency of instruction.

Although frequency-based lists answer the question of what to study, how to study must also be addressed. Successful vocabulary learning involves a combination of implicit and explicit instruction, meaningful engagement, and repeated meetings with words (Nation, 2013), facilitated by careful integration of words into a curriculum, systematic instruction, and repetition. However, such an intensive approach can be poorly implemented in many instructional contexts when important components of systematic instruction and curriculum integration are missing (Barker, 2007). Although instructors often refer to frequency-based lists when leveling materials and selecting words, the impact of such endeavors might be reduced 
when subsequent instructors adopt such an approach, attenuating the rate at which students can learn new words and expand coverage. In programs lacking sufficient coordination, the learners, not the materials or instructors, are the most stable elements in the system (Barker, 2007), and training learners to take responsibility for vocabulary development might be more sustainable.

For those studying an L2 to engage in a specific field, there are additional complications in vocabulary selection. The most frequent vocabulary between fields often differs, and language instructors might be limited in their knowledge of what vocabulary would be most useful in a particular field, a problem that is exacerbated as study becomes more specialized (Anthony, 2018). For specialized fields, developing students' study skills might be more efficacious than relying on their instructors or using readily available frequency-based lists, which might not be specific to their fields of study.

One way to develop learners' ability to study vocabulary is through the use of vocabulary notebooks, which have been shown to be effective pedagogical tools (e.g., Walters \& Bozkurt, 2009). Although vocabulary notebooks are not novel, technology has allowed for new adaptations. Platforms such as Google Sheets (http://sheets.google.com/) present an opportunity for learners to collaborate and build a shared "notebook" to drive vocabulary learning. These student-created class vocabulary lists (CVLs) have the potential to increase motivation through a combination of collaborative and autonomous learning while simultaneously developing the ability to choose and study vocabulary. The shared format allows CVLs to be integrated into classroom activities and assessment, blending independent learning and classroom instruction.

\section{Methodology}

In this exploratory study, we examined CVLs and student word choice across two different classroom contexts using the Compleat Web Vocabulary Profiler (Web VP; Cobb, n.d.), AntConc (Anthony, 2019a), and AntCorGen (Anthony, 2019b). We hypothesized that students would generally choose relevant and useful words for their own learning contexts. However, it was unclear to what degree choices would overlap with publically available lists (i.e., NGSL, TSL, BNC/ COCA) that contain the most useful words of English based on frequency, or to what degree students would choose words specifically relevant to their major.

\subsection{Participants}

The study involved participants from two groups $(N=53)$. The first group involved a special advanced English program for non-English majors at a women's university in Japan. Twenty-six students in second-year $(n=12)$, third-year $(n=10)$, and fourth-year $(n=4)$ cohorts participated over two semesters. The second group involved a required English communication course for first-year students in the science and technology department at a coeducational university in Japan. One class of first-year informatics students $(n=27)$ participated over one semester. 


\subsection{Student-Created Class Vocabulary Lists}

A CVL for each class - three in the first group, one in the second group - was created using Google Sheets. Editing permission was granted to students, allowing for simultaneous access during study, homework, and in-class activities. Students had access to their class' sheet only. Based on the vocabulary notebook recommendations of Schmitt and Schmitt (1995), the spreadsheet included columns for the English word, the Japanese translation, a pronunciation code, the part of speech, a usage example, and related words. The pronunciation code (B. Teaman, personal communication, February, 2018) consisted of two digits: the first being the number of syllables in the word and the second being the stressed syllable. The code was intended to direct students' attention to the phonology of words in addition to the orthography. Students were asked to include an example sentence that clearly showed the meaning of the word. The related words column was intended to help integrate new vocabulary into existing lexical networks as "the best way to remember new words is to incorporate them into language that is already known" (Schmitt \& Schmitt, 1995, p. 133).

To build the CVLs, students were required to choose words that they deemed useful or important and complete each column in the spreadsheet. Although students were given autonomy, they were instructed on how to make good choices following Barker's (2007) guiding questions. Before choosing words, students were encouraged to ask themselves, "Have I seen it more than once?" "Would I use the translation of this word in my language?" and "Do I have a special reason for wanting to know this word?" among others (see Barker's guidelines for a full list). Instructors worked as curators, correcting errors when necessary and possible.

In the first group, participants added three words every week for two semesters. To direct students' attention to common words, NGSL and TSL words were identified using the Web VP (Cobb n.d.) and highlighted by the instructor. CVLs were used to make quizzes and activities for each class. A partial CVL created by second-year participants in the first context is shown in Figure 1.

\begin{tabular}{|c|c|c|c|c|c|c|}
\hline & A & B & c & D & E & $\mathrm{F}$ \\
\hline 1 & English & Japanese & Pronunciation & Part of Speech & Related words & Example Sentence (show meaning clearly) \\
\hline 441 & prominently & 目立って、顕著に & $4-1$ & adverb & $\begin{array}{l}\text { stand out, outstandingly, } \\
\text { marked, noticeable }\end{array}$ & $\begin{array}{l}\text { Many designers display logo prominently on clothes and } \\
\text { bags. }\end{array}$ \\
\hline 442 & engagement & 関与、参加、取り決め & 3-2 & noun & involvement, participation & $\begin{array}{l}\text { Japan continued political and economic engagement with } \\
\text { Asia countries. }\end{array}$ \\
\hline 443 & subtle & $\begin{array}{l}\text { 微妙な、複雑な、手の込ん } \\
\text { だ }\end{array}$ & $2-1$ & adjective & $\begin{array}{l}\text { unsubtle,complicated,diffic } \\
\text { ult,delicate }\end{array}$ & There are subtle differences between the two. \\
\hline 444 & scope & 範囲、視野 & $1-1$ & noun & visual field, view & $\begin{array}{l}\text { The teachers have to secure the wide activity scope for } \\
\text { children. }\end{array}$ \\
\hline 445 & bleak & 寒い、吹きさらしの & $1-1$ & adjective & cold, chilly & Hokkaido always blows a bleak wind in winter. \\
\hline 446 & vaccine & ワクチン & $2-2$ & noun & inject some vaccine & Children has to take vaccine for preventing some diseases. \\
\hline 447 & ban & 禁止する & $1-1$ & verb & Suppression,Oppose & He was banned from driving. \\
\hline 448 & criticism & 批判 & 4-1 & noun & referee,judgment & I read literary criticism. \\
\hline 449 & prevail & 優勢である & $2-2$ & verb & $\begin{array}{l}\text { advantageous, to be in the } \\
\text { lead }\end{array}$ & Right will prevail in the end. \\
\hline 450 & compliment & 䞉呈する、ほめる & $3-1$ & verb & give,praise & My supervisor complemented me on my work. \\
\hline 451 & forbidden & 禁じられた & 3-2 & adjective & prohibited, banned & It is forbidden to come in here. \\
\hline 452 & enterprise & 企業、事業、冒険心 & 3-1 & noun & & The enterprise is collecting a lot of attention. \\
\hline 453 & settlement & 合意、解決 & 3-1 & noun & agree, solve & I reach a settlement. \\
\hline 454 & dine & 食事をする & $1-1$ & verb & eat, diet & He dines out once a week. \\
\hline 455 & avenue & 大通り & $3-1$ & noun & road, big & There is an avenue of poplars. \\
\hline 456 & obvious & 明らかな & 3-1 & adjective & open,overt & I had some obvious errors in my test. \\
\hline
\end{tabular}

Figure 1. Example CVL accessible through a shared Google spreadsheet. 
In the second group, students considered topics they wanted to discuss in English, either related to their major or more general. Once topics were chosen (e.g., What are the good points of virtual reality?, What do you think about the Internet of things, etc.), students conferred in Japanese to decide what vocabulary would be necessary for those topics, and whether they knew those words in English. Unknown English words deemed necessary were added to the CVL. Each week students discussed one topic. After discussions, the CVL was reviewed and further words retrospectively deemed useful were added. Each student was asked to add three words to the CVL during the first six weeks of the semester. Students were free to focus on a single topic, however, they were encouraged to include words that could be used in a range of topics. Words on the CVL were tested as part of mid and end of term exams.

\subsection{Analysis}

To determine if students were choosing frequently occurring words, choices were compared against the NGSL, TSL, and BNC/COCA lists using the Web VP (Cobb, n.d.). These lists contain the most frequently used words in English (i.e., NGSL and BNC/COCA) and words needed for qualification testing (i.e., TSL), both considered important by the participants. Each CVL was analyzed to determine the degree of overlap between CVLs and the above-mentioned lists. Student choices not accounted for on the lists (i.e., off-list words) were also examined. Word types rather than tokens were examined to control for repetition.

For the second group, an additional comparison was made using a keyword list generated from an information technology (IT) corpus to determine how many words specific to the field of informatics had been selected. The corpus of 5,190 journal articles was created using AntCorGen (Anthony, 2019b) and included a subset of articles with computer and information sciences tags in the PLOS-One database. Articles with these tags but from PLOS publications other than the PLOS-One journal (e.g., PLOS Pathogens) were excluded. A keyword list for this corpus was created in AntConc (Anthony, 2019a) using the BNC word frequency list as the reference. Keyness values were calculated using a log-likelihood (four terms) keyword statistic with a $p<0.0001$ Bonferroni-corrected significance threshold. An odds ratio (OR) was calculated for effect size. Both keyness and OR were examined following Pojanapunya and Watson Todd (2018), who suggested that log-likelihood keyness highlights words of general use, while OR highlights more specialized words. Only words with keyness values greater than 1,000 were compared against the CVL.

\section{Results and Discussion}

In the first group, second-, third-, and fourth-year students chose 504, 490, and 208 word items, respectively, while informatics students in the second group chose 111.

The distribution of word types by percentage is shown in Tables 1 and 2, while visualizations are shown in Figures 2 and 3.

Results suggest that students largely chose words considered useful in general. The majority of choices made by second-year $(64.09 \%)$ and third-year 
Table 1. Percentage of Total Tokens for Word Types by List (NGSL/TSL)

\begin{tabular}{lcccc}
\hline & Year 2 & Year 3 & Year 4 & Informatics \\
\hline NGSL 1 & 13.10 & 16.12 & 12.50 & 30.6 \\
NGSL 2 & 17.06 & 17.76 & 14.42 & 26.1 \\
NGSL 3 & 13.10 & 14.29 & 12.02 & 11.7 \\
TSL & 20.83 & 18.78 & 6.25 & 9.0 \\
Total on-list & 64.09 & 66.95 & 45.19 & 77.4 \\
Off-list & 35.71 & 32.86 & 54.33 & 22.52 \\
\hline
\end{tabular}

Note: Due to rounding, percentage totals might not equal to 100 .

Table 2. Percentage of Total Tokens for Word Types by List (BNC/COCA)

\begin{tabular}{lcccc}
\hline Frequency level & Year 2 & Year 3 & Year 4 & Informatics \\
\hline K1 & 15.87 & 14.08 & 12.98 & 27.0 \\
K2 & 17.26 & 20.61 & 17.79 & 34.2 \\
K3 & 29.37 & 29.18 & 27.88 & 22.5 \\
K4 & 11.90 & 10.20 & 11.54 & 7.2 \\
K5 & 11.71 & 6.33 & 6.73 & 0.9 \\
K6 & 4.56 & 4.08 & 7.69 & - \\
K7 & 3.37 & 4.08 & 2.40 & 1.8 \\
K8 & 1.19 & 2.04 & 1.44 & - \\
K9 & 0.40 & 1.43 & 2.88 & 1.8 \\
K10 & 0.20 & 0.61 & 1.44 & - \\
K11 & 0.40 & 0.61 & 2.40 & 0.9 \\
K12 & - & 0.61 & 1.44 & - \\
K13 & 0.20 & 0.61 & - & - \\
K14 & 0.40 & - & 0.48 & - \\
K15 & 0.20 & - & - & - \\
K16 & 0.40 & - & 0.48 & - \\
K17 & 0.20 & - & - & - \\
K18 & - & - & - & 0.9 \\
K19 & 0.20 & - & - & - \\
Off-list & 1.98 & 5.31 & 1.92 & 2.7 \\
\hline
\end{tabular}

Note: Due to rounding, percentage totals might not equal to 100 . Words beyond the K19 band were not selected.

$(66.95 \%)$ students in the first group and informatics majors $(77.4 \%)$ in the second group were covered by NGSL and TSL. Informatics students chose a greater proportion of high-frequency words, possibly due to the focus on speaking tasks in their course. The exception was fourth-year students in the first group whose off-list choices constituted $54.33 \%$ of their CVL. This difference can partially be explained by the advanced level of those students and the content of the fourthyear discussion course, which focused on authentic materials from English news sources. Off-list choices such as denuclearization, noncompliance, and statesman were all chosen from news articles. Similarly, aftershock and heatstroke were selected by third-year students due to their relative importance in Japan, as were 


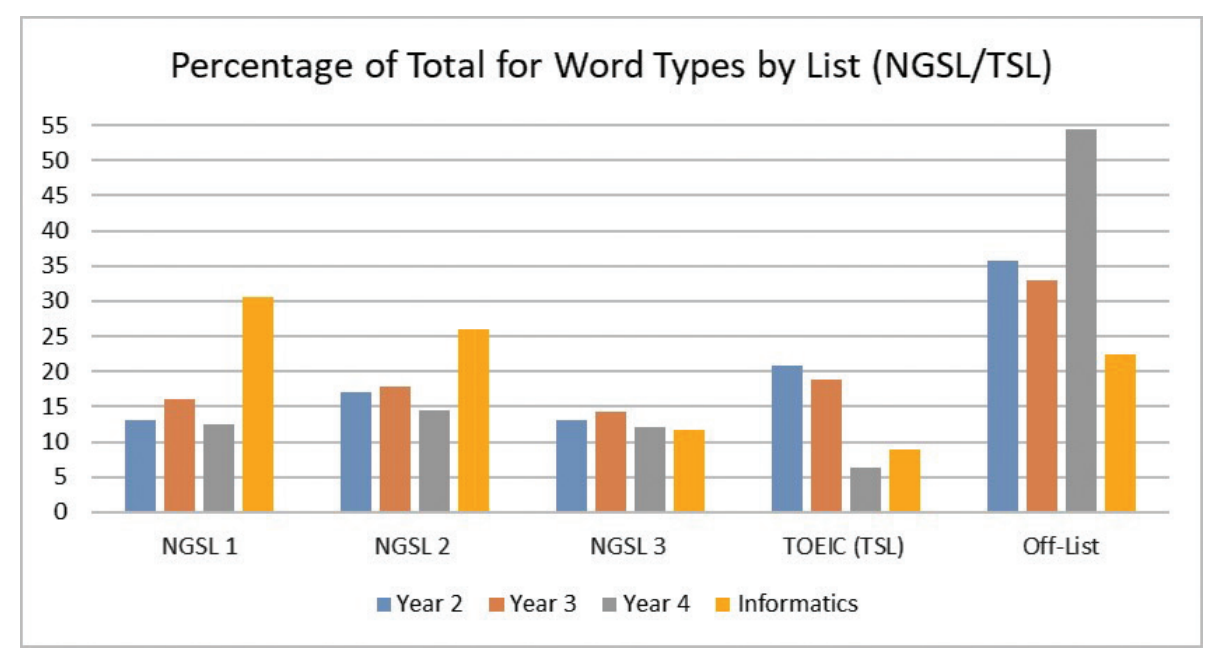

Figure 2. Percentage of total for word types by list (NGSL/TSL) for each class.

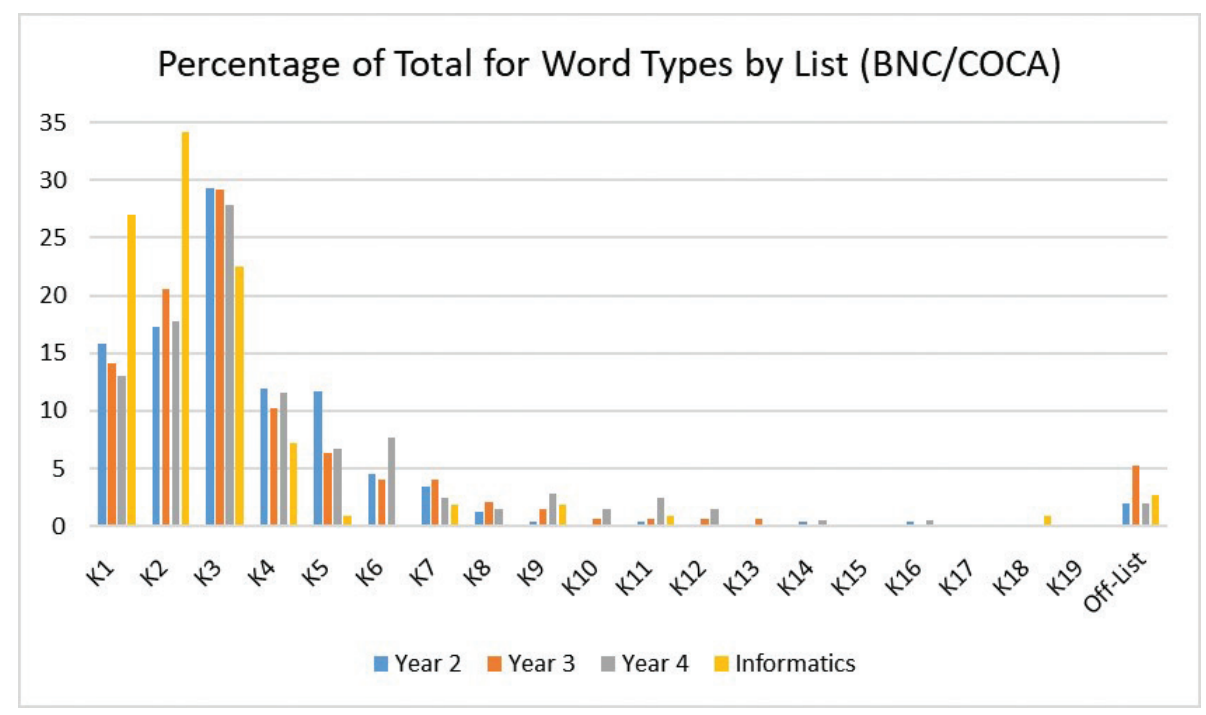

Figure 3. Percentage of total for word types by list (BNC/COCA) for each class.

landslide and blackout, by the informatics students. These choices suggest that there was often a clear learning goal when off-list words were selected.

As for words selected by informatics students, 24 (21.6\%) also appeared on the IT keyword list (see Table 3), indicating that students selected several words that were also relevant to their major. Of these items, five are not present on the NGSL or TSL lists, suggesting that they would not have been targeted for instruction were only these frequency-based lists considered. 
Table 3. Keyness/OR Measures of Words Appearing on Both Informatics Keyword and CVL

\begin{tabular}{|c|c|c|c|c|c|}
\hline Word & Keyness & OR & Word & Keyness & OR \\
\hline internet & $37,487.76$ & 428.84 & artificial* $^{*}$ & $2,647.48$ & 4.59 \\
\hline analyze & $7,733.27$ & 90.79 & machine & $11,694.47$ & 4.48 \\
\hline simulation* & $15,672.22$ & 44.32 & information & $44,574.81$ & 4.24 \\
\hline network & $64,622.88$ & 15.54 & systematic* & $1,866.29$ & 4.11 \\
\hline virtual $^{*}$ & $5,342.87$ & 11.53 & automatic & $2,073.74$ & 3.70 \\
\hline calculation & $4,944.32$ & 9.73 & activity & $9,119.85$ & 3.53 \\
\hline function & $31,904.28$ & 8.38 & laboratory & $1,652.26$ & 3.15 \\
\hline privacy* & $2,489.99$ & 6.38 & introduction & $3,983.04$ & 3.14 \\
\hline measure & $13,998.50$ & 6.01 & memory & $4,152.26$ & 3.01 \\
\hline brain & $9,148.65$ & 5.53 & useful & $1,065.34$ & 1.77 \\
\hline procedure & $8,873.39$ & 4.96 & decision & $1,216.07$ & 1.59 \\
\hline programming & $1,971.54$ & 4.72 & real & $1,377.53$ & 1.56 \\
\hline
\end{tabular}

Note: *Denotes off-list word (NGSL/TSL).

\section{Conclusion}

Frequency-based lists have aided instructors, administrators, and materials writers in deciding what vocabulary should be targeted for instruction; however, the results of this study indicate that CVLs also have potential benefits. One advantage is that learners using CVLs choose relevant vocabulary at appropriate times, which is important in English for specific purposes (ESPs) contexts. Although a keyword list for a particular major could be constructed, its utility would be limited by the extent to which underlying concepts had already been established (Nation, 2008). Using CVLs mitigates this issue as students choose vocabulary based on known or recently encountered concepts, particularly useful when instructors are not experts in learners' fields.

In general contexts, a learner-centered approach has the potential to increase relevance and engagement, thereby enhancing the learning environment while using CVLs to develop learners' ability to choose and study vocabulary independently might be more effective in the long-term than teacher-fronted approaches that cannot assist learners beyond graduation. The fact that the majority of vocabulary selected was on-list (NGSL/TSL) for all except the fourthyear students also indicates that learners are capable of selecting words that are useful long term. Even for fourth-year students, off-list choices were reasonable and useful considering the learning context and represent a shift toward less frequent vocabulary as learning progresses.

Although we certainly do not argue against the use of frequency-based lists, CVLs have the potential to help develop not only vocabulary, but also important language learning skills that facilitate sustainable learning. There is clear potential to improve vocabulary instruction through further research examining effective ways in which frequency-based lists and CVLs can be used together. 


\section{References}

Anthony, L. (2018). Introducing English for specific purposes. London, England: Routledge.

Anthony, L. (2019a). AntConc (Version 3.5.8). Retrieved from https://www. laurenceanthony.net/software

Anthony, L. (2019b). AntCorGen (Version 1.1.2). Retrieved from https://www. laurenceanthony.net/software

Barker, D. (2007). A personalized approach to analyzing "cost" and "benefit" in vocabulary selection. System, 35(4), 523-533. doi: 10.1016/j.system.2007.09.001

Browne, C., \& Culligan, B. (2016). The TOEIC service list. Retrieved from http:// www.newgeneralservicelist.org

Browne, C., Culligan, B., \& Phillips, J. (2013). The new general service list. Retrieved from http://www.newgeneralservicelist.org

Cobb, T. (2019). Compleat Web VP (Version 2). Retrieved from https://www.lextutor. $\mathrm{ca} / \mathrm{vp} /$

Nation, I. S. P. (2008). Teaching vocabulary: Strategies and techniques. Boston, MA: Heinle.

Nation, I. S. P. (2012). The BNC/COCA word family lists. Retrieved from http:// www.victoria.ac.nz/lals/about/staff/paul-nation

Nation, I. S. P. (2013). Learning vocabulary in another language (2nd ed.). Cambridge, England: Cambridge University Press.

Pojanapunya, P., \& Watson Todd, R. (2018). Log-likelihood and odds ratio: Keyness statistics for different purposes of keyword analysis. Corpus Linguistics and Linguistic Theory, 14(1), 133-167. doi: 10.1515/cllt-2015-0030

Schmitt, N., \& Schmitt, D. (1995). Vocabulary notebooks: Theoretical underpinnings and practical suggestions. ELT Journal, 49(2), 133-143. doi:10.1093/ elt/49.2.133

Walters, J., \& Bozkurt, N. (2009). The effect of keeping vocabulary notebooks on vocabulary acquisition. Language Teaching Research, 13(4), 403-423. doi: $10.1177 / 1362168809341509$ 